\title{
PENGEMBANGAN SISTEM INFORMASI SERVICE KENDARAAN PADA BENGKEL KFMP
}

\author{
Yohannes Yahya Welim \\ Fakultas Teknologi Informasi, Program Studi Sistem Informasi \\ Universitas Budi Luhur \\ Email: yahyab188@yahoo.com
}

T.W. Wisjhnuadji

Program Studi Sistem Komputer

Universitas Budi Luhur

Email: wisnoex@yahoo.com

\author{
Rasip Firmansyah \\ Program Studi Sistem Informasi \\ Universitas Budi Luhur \\ Email: yohannes_bl@yahoo.com
}

\begin{abstract}
ABSTRAK
Perkembangan teknologi informasi yang pesat saat ini telah memasuki hampir semua kehidupan. Hal ini ditandai dengan banyaknya pengguna komputer, baik untuk kepentingan perusahaan atau bisnis sampai kepada hal-hal yang bersifat hiburan dan pendidikan.Pesatnya perkembangan bisnis yang mengadaptasi teknologi informasi, mendorong terjadinya persaingan bisnis, Setiap pelaku bisnis bersaing untuk merebut pangsa pasar dan meraih pelanggan yang mau menggunakan produk atau jasa dari perusahaannya.Bengkel KFMP adalah usaha milik perorangan yang bergerak dibidang jasa yaitu perbaikan mobil khususnya spesialis untuk mobil-mobil produksi dari Honda atau mobil buatan jepang seperti CRV. Untuk setiap perbaikan kendaraan, bengkel tersebut harus melakukan pencatatan dan perhitungan administrasi service. Proses penyelesaian transaksi tersebut sampai sekarang masih menggunakan sistem manual, mulai dari proses pendaftaran pelanggan maupun pendataan tanda pembayaran serta pembuatan laporan yang ditujukan kepada kepala bengkel. Sehingga, hal ini menjadi salah satu penyebab terhambatnya proses pelayanan terhadap para pelanggan dan keterlambatan informasi yang akan disampaikan kepada kepala bengkel. Hasil yang diperoleh dari pengembangan sistem ini adalah dengan melakukan tahapan analisa sistem, analisa analisa perancangan sistem dan perancangan basis data sehingga mempermudah kegiatan perusahaan, mengolah data, membuat laporan menjadi lebih mudah dan efisien, penyajian informasi yang akurat, relevan dan tepat waktu membuat pihak manajemen dalam mengambil keputusan.
\end{abstract}

Kata kunci: bengkel, informasi, bisnis

\begin{abstract}
The Rapid development of information technology has now entered almost all life. It is characterized by the number of computer users, either for the company or business up to the things that are fun and educational. The rapid development of information technology to adapt the business, encouraging business competition, every businessperson vying for market share and reach customers who want to use the products or services of the company. KFMP workshop is individually owned businesses engaged in auto repair services that specialize in particular for the production cars from honda or a car made in japan like crv. For each vehicle repairs, the workshop must keep records and calculations administration service. The process of settlement of such transactions are still using manual systems, ranging from customer registration and data collection process payments signs and preparing reports addressed to the head of the workshop. Thus, it is becoming one of the causes of delays to the customer service process and delay information to be submitted to the head of the workshop. The results obtained from the development of this system is to perform system analysis stage, the analysis system design analysis and database design that eases the company, process data, create reports become easier and efficient, presenting information that is accurate, relevant and timely make management in making decisions.
\end{abstract}

Keywords: workshop, information, business 


\section{PENDAHULUAN}

\subsection{Latar Belakang}

Teknologi informasi sangat diperlukan semua orang, baik pribadi, perusahaan yang hampir semua bidang bisnisnya. Hal ini ditandai dengan banyaknya pengguna komputer, baik untuk kepentingan perusahaan atau bisnis sampai kepada hal-hal yang bersifat hiburan dan pendidikan. Pesatnya perkembangan bisnis yang mengadaptasi teknologi informasi, mendorong terjadinya persaingan bisnis. Setiap pelaku bisnis bersaing untuk merebut pangsa pasar dan meraih pelanggan agar menggunakan produk atau jasa dari perusahaannya.

Bengkel KFMP adalah usaha milik perorangan yang bergerak dibidang jasa yaitu perbaikan mobil khususnya spesialis produksi dari Honda atau mobil buatan jepang seperti CRV, JAZZ, CIVIC, CITY. Saat ini Bengkel KFMP dalam aktivitas usahanya masih menggunakan sistem manual dan belum menggunakan sistem komputer mulai dalam hal mengelola data pelanggannya hingga membuat laporan keuangan.

\subsection{Rumusan Masalah}

Sistem saat ini bengkel KFMP mempunyai masalah yaitu pada pencarian data pelanggan membutuhkan waktu yang lama, karena semuanya dikerjakan masih menggunakan sistem manual. Pembuatan Laporan masih terdapat kesalahan, sering terlambat sehingga pengambilan keputusan juga terlambat.

\subsection{Tujuan}

Melakukan pengembangan sistem informasi service kendaraan untuk menjawab permasalahan yang terjadi saat ini agar pelanggan merasakan pelayanan yang lebih baik..

\subsection{Tinjauan Pustaka}

\subsubsection{Konsep Dasar Sistem}

Sistem dalam bidang sistem informasi adalah Sekelompok komponen yang saling berhubungan, bekerja sama untuk mencapai tujuan bersama dengan menerima proses input serta menghasilkan input dalam proses transformasi yang teratur [1]. Sistem adalah suatu jaringan kerja dari prosedur-prosedur yang saling berhubungan, terkumpul bersama-sama untuk melakukan suatu kegiatan atau untuk tujuan tertentu [2].

\subsubsection{Konsep Dasar Informasi}

Informasi adalah hasil dari pengolahan data dalam suatu bentuk yang lebih berguna dan berarti bagi penerimanya yang menggambarkan suatu kejadian-kejadian (event) yang nyata digunakan untuk pengambilan keputusan. Data dan informasi merupakan sebuah pondasi untuk memahami konsep sistem informasi [1]. Informasi dapat memiliki kualitas yang tergantung pada kriteria berikut :

a. Akurat Informasi harus bebas dari kesalahan-kesalahan dan tidak biasa atau menyesatkan.

b. Tepat pada waktunya Informasi yang diberikan atau datang pada penerima tidak boleh terlambat.

c. Relevan Informasi tersebut mempunyai manfaat untuk pemakainya. Suatu sistem informasi dikatakan bernilai bila manfaatnya lebih efektif dibanding dengan biaya pendapatannya.

d. Lengkap Informasi yang dikirim harus lengkap agar tidak salah pemahamannya.

\subsubsection{Konsep Dasar Sistem Informasi}

Pengertian sistem informasi adalah Sistem informasi yang saling berikatan untuk memberikan data, memproses, dan menyimpan satu sama lain yang membentuk satu kesatuan informasi [1]. 


\subsubsection{Konsep Dasar Analisa Sistem}

Analisa sistem adalah penguraian suatu sistem informasi yang utuh kedalam bagian komponennya yang bertujuan untuk mengidentifikasikan dan mengevaluasikan permasalahan, kesempatan, hambatan yang terjadi dan menentukan kebutuhan sehingga dapat diusulkan perbaikannya. Adapun Langkahlangkah dalam analisa secara umum sebagai berikut :

a) Analisa Pendahuluan

Dalam analisa pendahuluan ini dilakukan pengumpulan informasi yang memperoleh gambaran secara menyeluruh mengenai tempat yang akan kita analisa. Pelaksanaan analisa sistem dirancang oleh analisa sistem dalam suatu dokumen tertulis yang disebut usulan pelaksanaan sistem. Maksud dihasilkannya dokumen tertulis tersebut adalah untuk mempertemukan pikiran pemakai informasi dengan analis sistem untuk memenuhi kebutuhan pemakai informasi.

b) Pelaksanaan analisa sistem

Pelaksanaan analisa sistem didasarkan pada rancangan kerja yang dituangkan dalam usulan analisa sistem.

c) Penyusunan laporan hasil analisa sistem

Hasil akhir analisa sistem disajikan dalam bentuk suatu laporan yang berguna dalam pengambilan keputusan

\subsubsection{Konsep Dasar Service Kendaraan}

a) Pengertian Service (Perbaikan)

Service sering disebut dengan istilah perbaikan (jasa), Pengertian dari perbaikan itu sendiri adalah usaha untuk mengembalikan kondisi dan fungsi dari suatu benda atau alat yang rusak akibat pemakaian alat tersebut pada kondisi semula. Proses perbaikan tidak menuntut penyamaan sesuai kondisi awal, yang diutamakan adalah alat tersebut bisa berfungsi normal kembali.

Perbaikan memungkinkan untuk terjadinya pergantian bagian alat/sparepart. Terkadang dari beberapa produk yang ada dipasaran tidak menyediakan sparepart untuk penggantian saat dilakukan perbaikan, meskipun ada, harga sparepart tersebut hampir mendekati harga baru satu unit produk tersebut. Hal ini yang memaksa user/pelanggan untuk membeli produk yang baru.

Tidak setiap perbaikan dapat diselesaikan dengan mudah, tergantung tingkat kesulitan dan kerumitan assembling / Perakitan alat tersebut. Tingkat kesulitan tersebutlah yang menumbuhkan perbedaan jenis perbaikan, mulai jenis perbaikan ringan, perbaikan sedang, dan perbaikan yang sering dinamakan service berat. Dari jenis service di atas ditentukan biaya perbaikan sesuai dengan tingkat kesulitan.

b) Unsur-unsur yang terdapat pada service kendaraan :

1. Bengkel

Bengkel adalah tempat (bangunan atau ruangan) untuk perawatan/pemeliharaan, memperbaiki, modifikasi alat dan mesin, tempat pembuatan bagian mesin dan perakitan mesin.

2. Mobil

Konstruksi dasar sebuah mobil dapat dibagi menjadi lima bagian utama, yaitu mesin, pemindah daya, casis, kelistrikan, dan body.

a. Mesin (engine) pada mobil adalah pembangkit tenaga gerak. Pada umumnya mesin yang digunakan pada mobil merupakan mesin pembakaran dalam (internal combustion engine) yang menggunakan piston (reciprocating piston) dalam pengubahan energi bahan bakar menjadi tenaga gerak. Lebih khusus lagi, mesin pembakaran dalam yang umum digunakan pada mobil adalah jenis mesin bensin dan diesel.

b. Pemindahan daya (power train) adalah suatu mekanisme yang memindahkan tenaga dari mesin ke roda-roda.

c. Casis adalah rangka mobil yang terdiri atas sistem suspense, sistem kemudi roda dan sistem rem.

d. Kelistrikan mesin terdiri dari atas bagian-bagiannya, yaitu batere (aki) yang menyuplai listrik ke komponen kelistrikan lainnya, sistem pengisian yang mensuplai listrik ke batere, sistem starter yang memutarkan mesin pemulaan, sistem pengapian yang membakar campuran udara bahan bakar yang dihisap ke dalam silinder. 
e. Kelistrikan mesin terdiri dari atas bagian-bagiannya, yaitu batere(aki) yang menyuplai listrik ke komponen kelistrikan lainnya, sistem pengisian yang mensuplai listrik ke batere, sistem starter yang memutarkan mesin pemulaan, sistem pengapian yang membakar campuran udara bahan bakar yang dihisap ke dalam silinder.

f. Body adalah bagian penutup atau pelindung dari sebuah mobil.

\section{Sparepart}

Sparepart adalah suatu barang yang terdiri dari beberapa komponen yang membentuk satu kesatuan dan mempunyai fungsi tertentu. Setiap alat berat terdiri dari banyak komponen, namun yang akan dibahas komponen yang sering mengalami kerusakan dan penggantian. Ada beberapa komponen yang juga terdapat didalamnya beberapa komponen kecil, misalkan engine yang mempunyai komponen didalamnya beberapa komponen kecil, misalkan engineyang mempunyai komponen didalamnya yaitu fuel injection pump, water pump, starting motor, alternator, oil pump, compressor, power steering pump, turbocharger, dan lain-lain. Setiap sparepart mempunyai fungsi tersendiri dan dapat terkait atau terpisah dengan sparepart lainnya. Misal starting motorkan terpisah fungsi kerjanya dengan alternator, walaupun secara tidak langsung juga ada hubungannya.Dimana alternator berfungsi untuk menghasilkan listrik untuk mengisi aki (accu/batere), sedangkan starting motor berfungsi untuk menghidupkan engine dengan menggunakan listrik dari aki. Secara umum sparepart dapat dibagi menjadi dua yaitu :

1. Sparepart baru yaitu komponen yang masih dalam kondisi baru dan belum pernah dipakai sama sekali kecuali sewaktu dilakukan pengetesan.

2. Sparepart bekas atau copotan yaitu komponen yang pernah dipakai untuk periode tertentu dengan kondisi :

a. Masih layak pakai yaitu secara teknis komponen tersebut masih dapat dipergunakan atau mempunyai umur pakai.

b. Tidak layak pakai yaitu secara teknis komponen tersebut sudah tidak dapat lagi dipakai walaupun dilakukan perbaikan atau rekondisi.

Pada kenyataan di lapangan, umumnya banyak pemakai yang lebih menyukai komponen/sparepart yang masih apa adanya (unrecondition). Mengingat komponen tersebut masih apa adanya setelah dilepas/dicopot dari alat berat atau truk, jadi masih dapat diindentifikasi kondisi sebenarnya. Jika diperlukan perbaikan atau rekondisi maka pemakai lebih yakin atas jenis suku cadang akan dilakukan penggantian. Sebenarnya penggunaan komponen bekas/copotan sudah lama dilakukan oleh pemakai alat berat di negara maju.Namun umumnya di negara maju, komponen yang dijual sudah dilakukan rekondisi dan siap pakai, serta distributor/supplier juga berani memberikan jaminan atas komponen tersebut.

Sedangkan di Indonesia baru beberapa tahun belakangan ini saja, banyak pemakai alat berat yang mencari komponen bekas/copotan.Mengingat harganya lebih murah sekali dibandingkan membeli komponen baru serta kebutuhan akan komponen bekas atau copotan semakin besar tiap tahunnya, tetapi kebutuhan tersebut akan semakin tidak seimbang dengan komponen bekas/copotan yang tersedia. Kecenderungan pemilik alat berat dan truk berusaha untuk memperpanjang umur pakai unit tersebut, jauh melebihi umur pakai di negara maju. Khusus pemakai yang belum berpengalaman dalam memakai komponen bekas/copotan, perlu lebih berhati-hati sewaktu memeriksa komponen tersebut, khususnya komponen yang sulit untuk melihat bagian dalam secara keseluruhan.hindari kesalahan pengamatan karena pada beberapa kejadian pihak penjual tidak mau komponen tersebut dikembalikan kalau sudah dibeli. Walaupun demikian bukan berarti bertransaksi atas komponen bekas/copotan sangat beresiko, hanya dibutuhkan ketelitian dalam pengamatan sebelum memutuskan untuk membeli.

\section{METODOLOGI PENELITIAN}

Metodologi yang digunakan dengan menggunakan metode berorientasi Obyek yang terdiri dari beberapa tahap yaitu : 


\subsection{Analisa Sistem}

Kegiatan yang dilakukan pada tahap ini adalah menganalisa sistem yang ada yaitu dengan mempelajari dan mengetahui apa yang dikerjakan sistem yang ada dan menspesifikasikan sistem yaitu dengan menspesifikasikan masukan yang digunakan, database yang ada, proses yang dilakukan dan keluaran yang dihasilkan. Adapun tahapan-tahapan pada analisa sistem antara lain :

a) Activity Diagram

Activity Diagram adalah alat untuk memodelkan alur kerja atau workflow sebuah proses bisnis dan urutan aktifitas didalam suatu proses.

b) Use Case Diagram

Use Case Diagram adalah alat untuk mendeskripsikan fungsi dari sebuah sistem dari perspektif pengguna.

c) Use Case Description adalah alat untuk mendeskripsikan secara rinci mengenal use case.

d) Entity Relationship Diagram

Entity Relationship Diagram adalah alat yang dapat mempresentasikan hubungan yang terjadi antara satu atau lebih komponen sistem.

\subsection{Perancangan Sistem}

Tahap Perancangan Sistem adalah merancang sistem secara rinci berdasarkan hasil analisa sistem yang ada, sehingga menghasilkan model sistem baru yang akan diusulkan, dengan disertai rancangan database dan spesifikasi program. Adapun tahapan - tahapan pada rancangan sistem antara lain :

a) Logical Record Structure

Logical Record Structure terdiri dari link-link diantara tipe record. Link ini menunjukkan arah dari satu tipe record lainnya.

b) Normalisasi

Normalisasi digunakan untuk mengorganisasikan file dengan menghilangkan grup elemen yang berulang atau sebuah langkah (proses) untuk menyederhanakan hubungan elemen data di dalam record.

c) Relasi

Relasi digunakan untuk mendefinisikan dan mengilustrasikan model konseptual secara terperinci dengan adanya primary key dan foreign key.

d) Spesifikasi Basis Data Spesifikasi basis data digunakan untuk menjelaskan tipe data yang ada pada model konseptual secara detail.

\subsection{Perancangan Basis Data}

Untuk menghasilkan basis data pada pengembangan system ini digunakan alat pemodelan yng disebut ERD (Entity Relationship Diagram). ERD ini kemudian ditransformasi ke LRS untuk menghasilkan Logical Record Structure lalu dinormalisasi hingga akhirnya akan didapat spesifikasi basis data yang baik.

\subsubsection{Entity Relationship Diagram}

Analisa data digunakan dengan memakai model ERD yaitu suatu diagram yang menggambarkan hubungan antar entitas yang ada pada sistem informasi service kendaraan yang dianalisa ini. Berawal dari $E R D$ inilah nantinya akan dihasilkan susunan basis data yang akan digunakan sebagai tempat menyimpan data. Lalu data tersebut digunakan sebagai bahan masukan untuk diolah pada tiap prosesnya dalam menghasilkan keluaran atau informasi yang diinginkan. Pada gambar 1 adalah hasil analisa data dari sistem service kendaraan bengkel WORKSHOP KFMP yang digambarkan dalam ERD. 


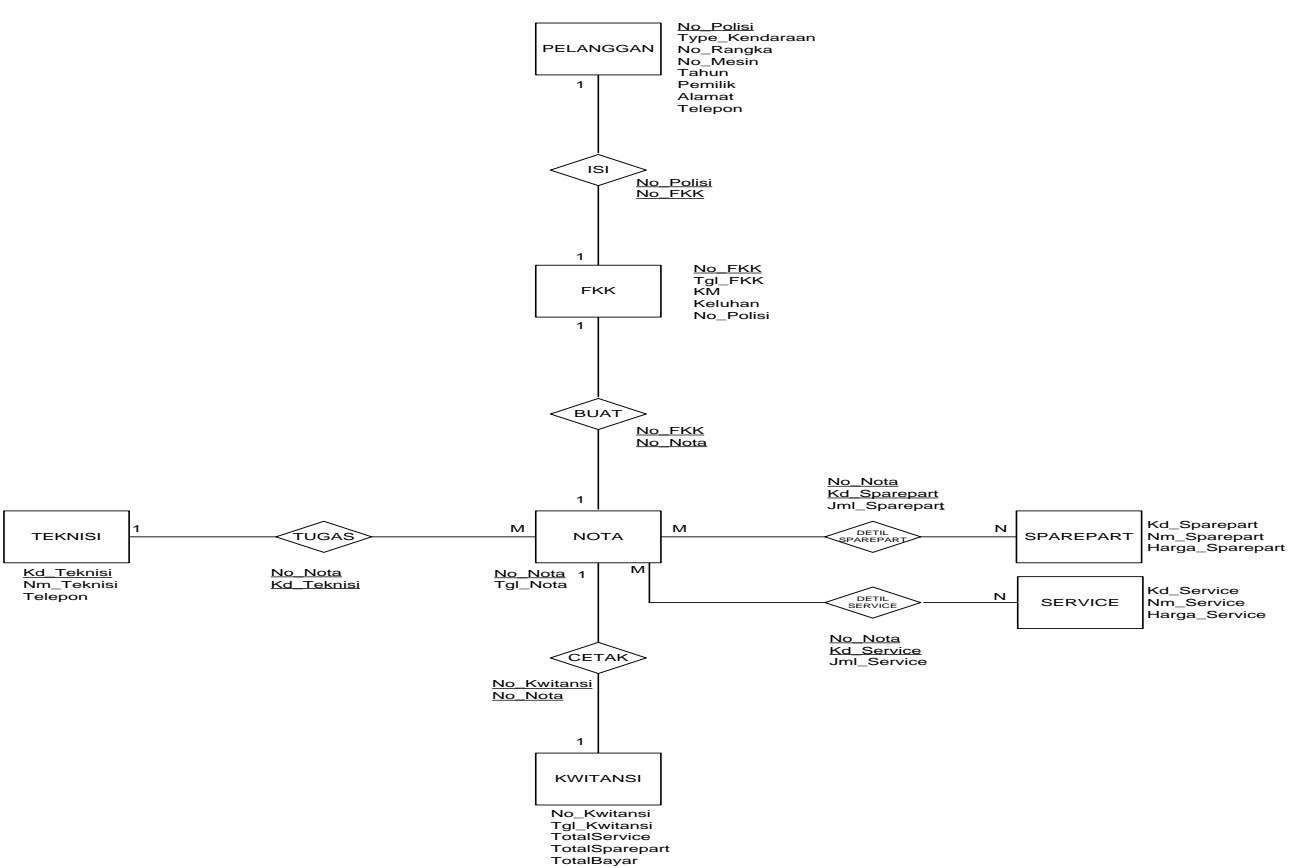

Gambar 1. Entry Relationship Diagram [3]

\subsubsection{Transformasi ERD ke LRS}

Hal yang perlu diperhatikan untuk mengubah $E R D$ dan $L R S$ ialah tingkatan kardinalitas pada $E R D$. Langkah-langkah seperti berikut :

a) Tingkatan kardinalitas satu ke satu, maka relasi akan digabung dengan entitas yang memerlukan acuan diantara dua entitas itu.

b) Tingkatan kardinalitas satu ke banyak, maka relasi akan digabung dengan entitas yang tingkat kardinalitasnya banyak.

c) Tingkatan kardinalitas banyak ke banyak, maka relasi akan berdiri sendirinya.

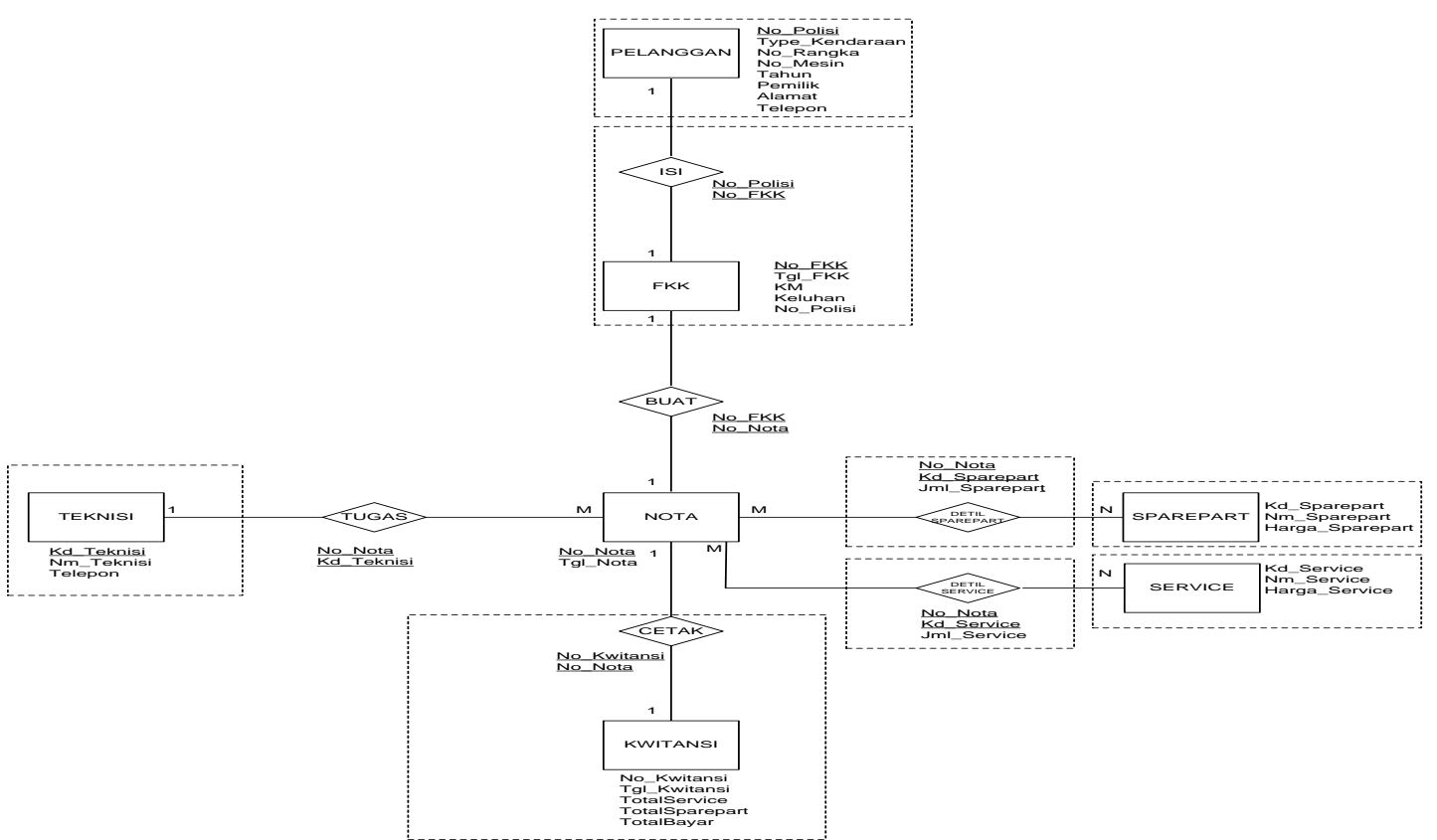

Gambar 2. ERD ke LRS [3] 


\subsubsection{Logical Record Strucuture (LRS)}

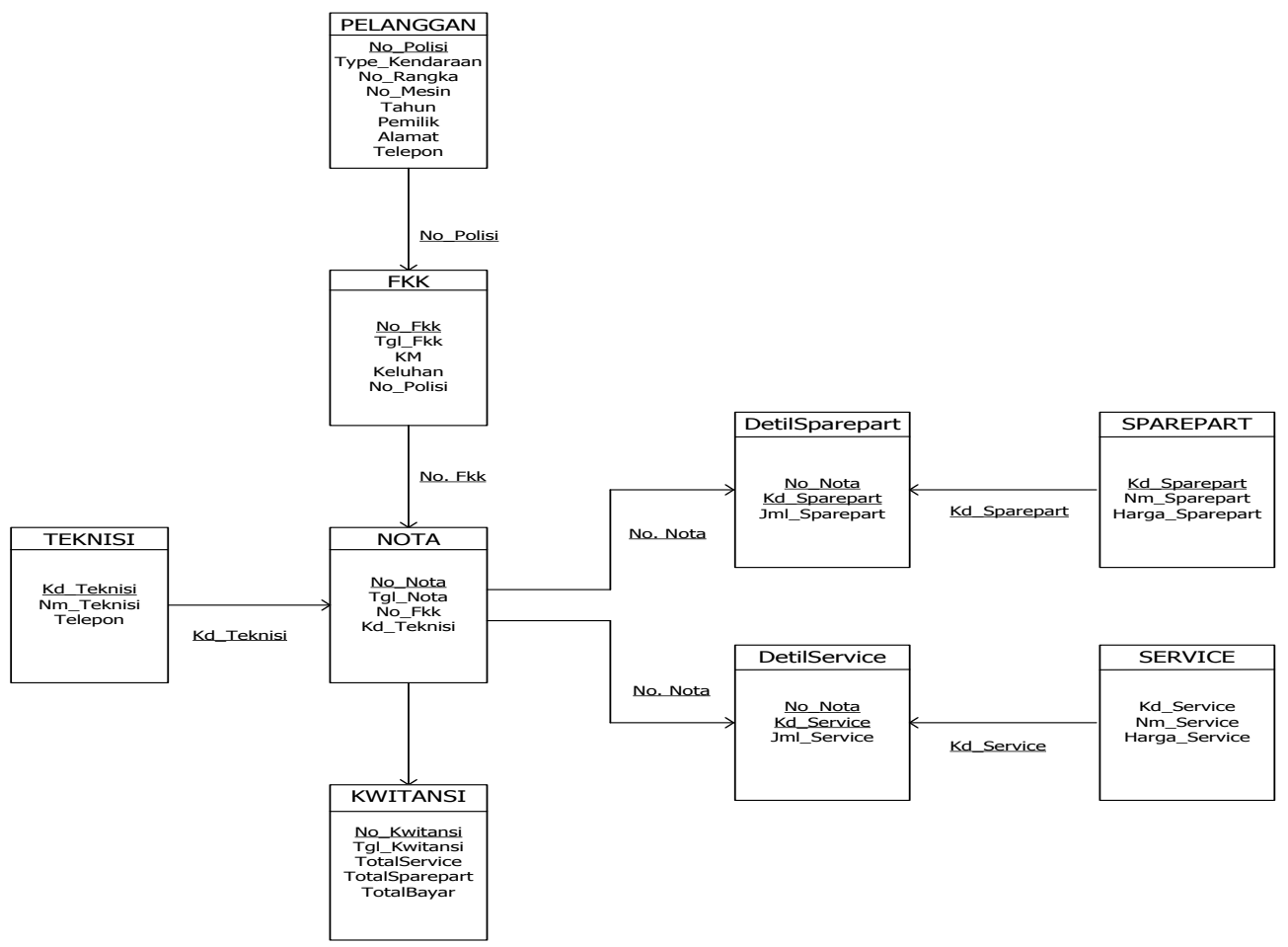

Gambar 3. Logical Record Structure [3]

\section{Hasil dAN PEMBAHASAN}

\subsection{Uraian Prosedur}

a. Pendaftaran Pelanggan

Tiap pelanggan yang akan memperbaiki kendaraannya diwajibkan untuk memberikan data-data kendaraannya tersebut ke Service Advisor dengan cukup menyerahkan STNK, kemudian Service Advisor mencatat data STNK tersebut pada form tanda terima. Form tanda terima tersebut berfungsi juga sebagai Form Keluhan Kendaraan (FKK) selain itu juga sebagai bukti penyerahan kendaran yang akan diperbaiki kepihak bengkel.

b. Proses pengerjaan Service

Service Advisor akan membuat nota sesuai dengan keluhan yang tercantum pada form serah terima atau form keluhan kendaraan yang selanjutnya memerintahkan kepada teknisi untuk menjalankan tugasnya, apabila ada penambahan penggantian sparepart yang tidak tercantum pada nota tersebut. Jika tugas teknisi selesai, maka Service Advisor mengkalkulasi biaya sesuai laporan dari teknisi. Setelah nota terisi jumlah biaya service, Service Advisor menyerahkan nota tersebut kepada kepala bengkel.

c. Pembayaran

Berdasarkan nota yang diberikan oleh Service Advisor, maka kasir segera membuat kwitansi yang kemudian diserahkan kepada pelanggan.

d. Pembuatan Laporan

Staf kasir merangkap staf administrasi, sehingga bertugas membuat laporan jasa service dan sparepart, laporan nota dan laporan teknisi tiap bulannya untuk dilaporkan kepada kepala bengkel.

\subsection{Analisa Proses}

Penganalisaan proses bertujuan untuk mengetahui proses yang terjadi pada bengkel KFMP. Analisa proses ini dapat dilihat dari Activity Diagram sistem yang sedang berjalan sebagai berikut : 
a. Pendaftaran Pelanggan

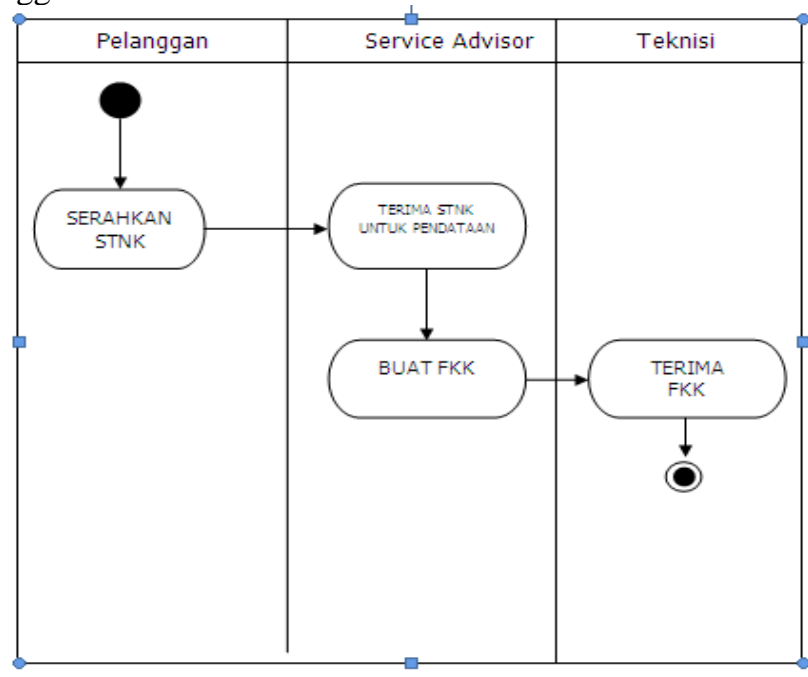

Gambar 4. Activity Diagram Pendaftaran Pelanggan

b. Proses Pengerjaan Service

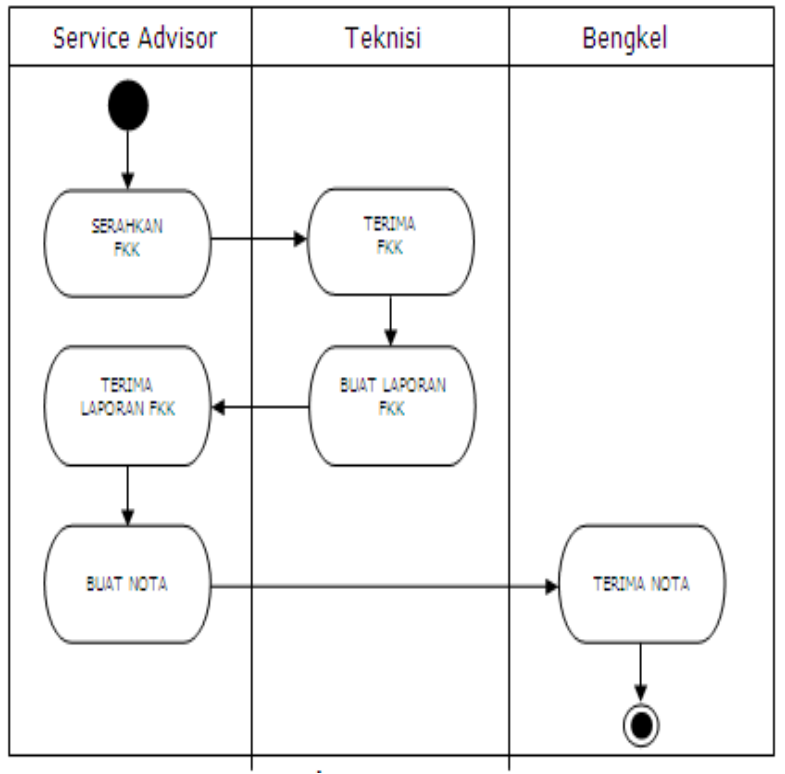

c. Pembayaran

Gambar 5. Activity Diagram Proses Pengerjaan Service

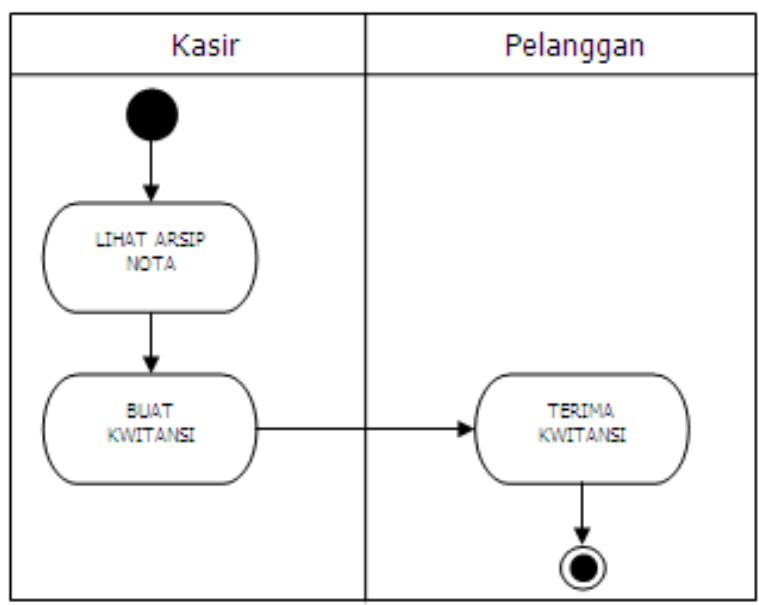

Gambar 6. Activity Diagram Pembayaran 
d. Pembuatan Laporan

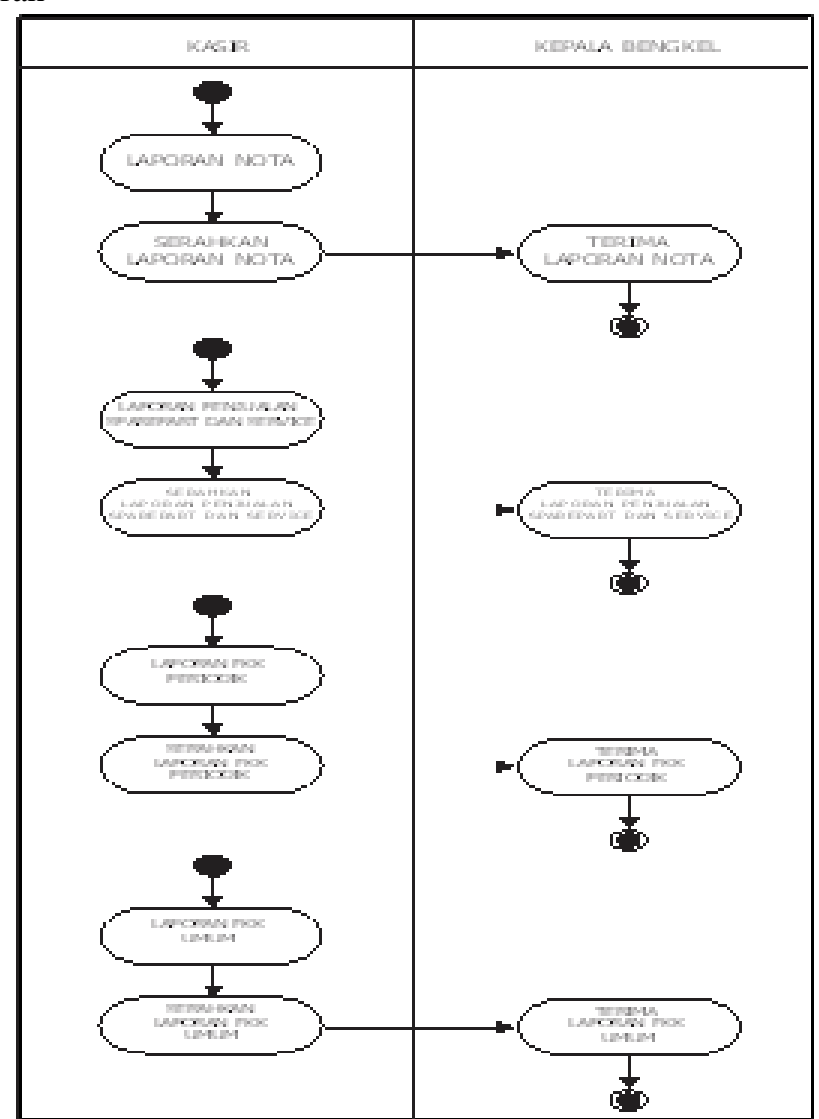

\subsection{Use Case Diagram}

Gambar 7. Activity Diagram Pembuatan Laporan

a. File Master

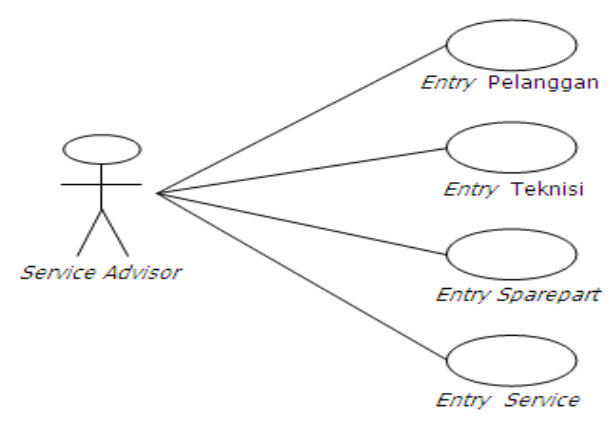

Gambar 8. Use Case File Master

b. File Transaksi

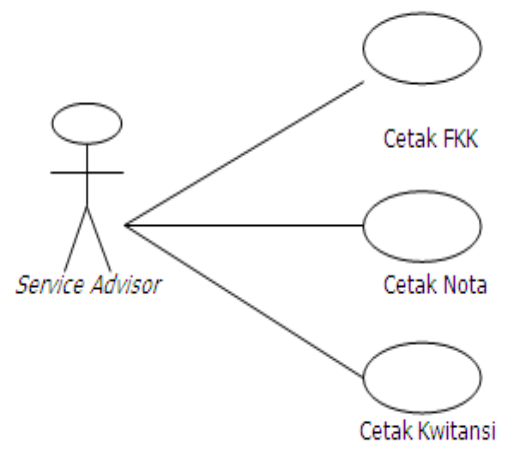

Gambar 9. Use CaseFile Transaksi 
c. File Laporan

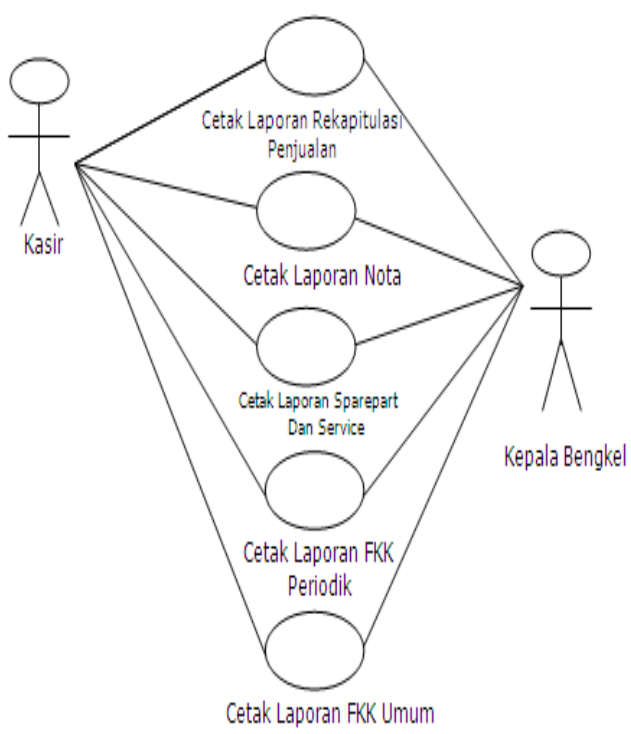

Gambar 10. Use Case File Laporan

\section{KESIMPULAN}

Kesimpulan yang didapat dari penyusunan rancangan sistem informasi service kendaraan pada bengkel KFMP adalah sebagai berikut :

a. Pengembangan sistem komputerisasi dapat membantu mempermudah kegiatan (operasional) perusahaan.

b. Pengolahan data dan pembuatan laporan penjualan sparepart dan service melalui sistem komputerisasi menjadi lebih mudah dan efisien.

c. Sistem komputerisasi dapat membantu manajemen dalam mengambil keputusan dengan menyajikan informasi yang akurat, relevan dan tepat waktu.

d. Pengembangan sistem informasi berbasis komputer dapat mengurangi kesalahan yang terjadi dan kemudahan dalam penelusuran sumber data.

\section{DAFTAR PUSTAKA}

[1] Mulyanto,Agus., 2008. Sistem informasi konsep dan aplikasi. Yogyakarta : Pustaka Belajar

[2] Yakub. 2012.. Pengantar Sistem Informasi. Yogyakarta : Graha Ilmu.

[3] Rusmawan, UUS. 2011. Koleksi Program VB.NET Untuk Tugas Akhir dan Skripsi. Jakarta : Penerbit PT. Elex Media Komputindo 